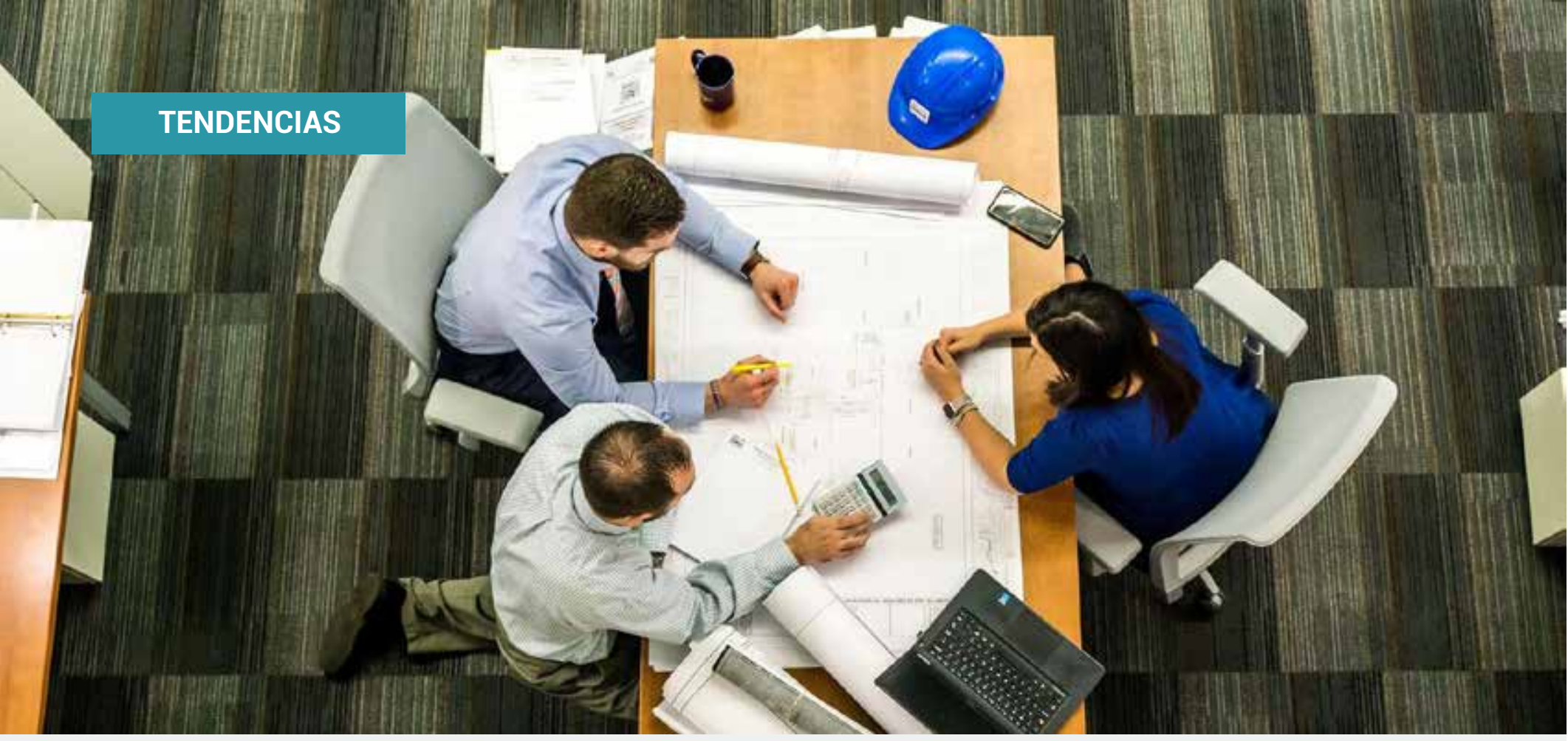

\title{
¿Cómo generar una transformación y actualización empresarial de éxito ante los grandes desafíos?
}

\section{Por. Jackye Sandoval}

Coach for Life•jackyesandovalcoachforlife@gmail.com

Estimado empresario, dedico este artículo a ustedes que desean dar esos primeros pasos hacia un nuevo modelo de servicio. Deseo que lo que voy a presentar aquí sea un aporte útil para la renovación, la innovación y el fortalecimiento de aquellas áreas de sus empresas que se debilitaron ante condiciones altamente significativas e inciertas como lo son las de una pandemia, la nueva normalidad o como quieran llamarlo.

Al inicio este escenario nos sumió en una dinámica de distanciamiento físico, con lo cual planteó limitaciones graves a las empresas que no estaban familiarizadas con estas condiciones de trabajo a distancia o tan digitalizadas.

Cada ámbito de nuestro que hacer empresarial debería ser analizado para así poder generar estratégicas condiciones que nos permitan dar un giro efectivo hacia la DIGITALIZACIÓN de sus empresas.

Con la aparición del Covid19 había un bajo porcentaje de empresas que ya estaban comenzando a digitalizarse, por esa razón tuvieron la posibilidad y la capacidad de responder mucho más rápido a las nuevas necesidades y condiciones. El escenario fue muy diferente para aquellas empresas que aún no contaban con las condiciones de digitalización. A las personas dueñas de empresas que buscaron adaptarse y fortalecer sus procesos de digitalización en menos de seis meses, que siguen en un proceso de mejora y adaptación es a quienes quiero dedicar este artículo.

Este artículo se desarrollará a través de cinco grandes dimensiones que responden a la necesidad de actualización de las empresas, es por eso por lo que las he nombrado como Las F5.

\section{Fortalecer el análisis de la situación actual:}

Ante los niveles de incertidumbre y cambios repentinos que nos lanzan las condiciones de una pandemia es necesario preguntarse ¿Qué ha funcionado? y ¿Qué no ha funcionado para las empresas ante los nuevos desafíos que una pandemia representa? En ese sentido, se deben evaluar los procesos internos y externos de la empresa, la tecnología disponible y la necesaria y a las personas de nuestro equipo actual. Esta evaluación debe apoyarse en tres elementos importantes para comenzar un proceso de transición.

El primero, establecer con claridad un D-O-F-A, porque para cada debilidad hay una oportunidad y para cada amenaza hay una fortaleza concreta que posteriormente será la base para el segundo elemento, un plan operativo por cada dimensión a analizar $y$, finalmente, el tercer elemento relevante es un compromiso de acción que nos permita llevarlo a la práctica y a la nueva realidad. 


\section{Y ACTUALIZACION EMPRESARIAL DE}
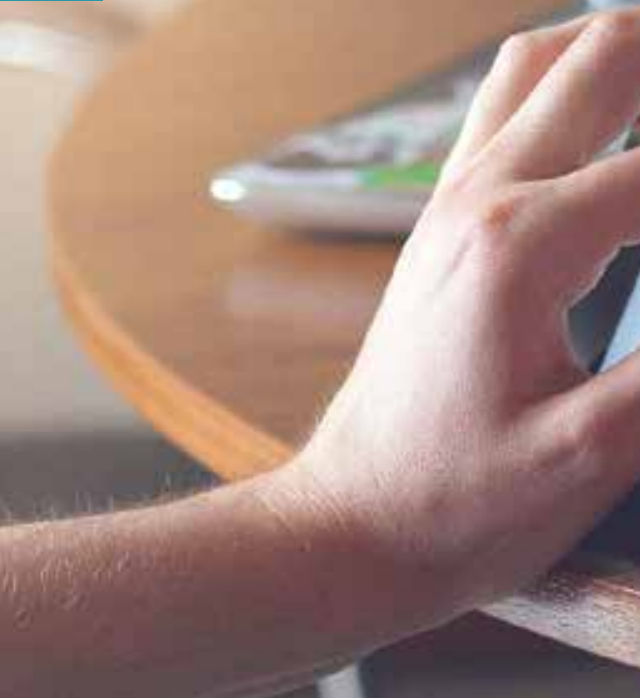

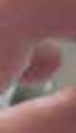
-
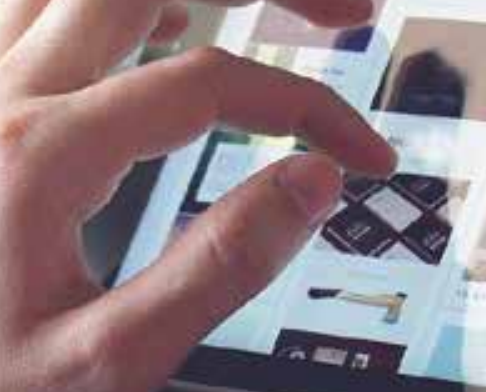

\section{Fortalecer al liderazgo:}

Con la actual situación es importante fortalecer y desarrollar el liderazgo de los mandos medios y que como equipo construyan y generen opinión con criterio informado para la implementación de iniciativas de transformación de los niveles de servicio en las empresas. Fortalecer estos liderazgos es necesario para desarrollar un referente sobre los nuevos comportamientos esperados dentro de las empresas, sobre el cumplimiento de metas y la gestión hacia la transición, la cual es hoy.

La forma para poder fortalecer este tipo de liderazgo es importante identificar a los nuevos líderes entre los equipos de trabajo, impulsar las carreras técnicas, entrenamientos en servicio al cliente en la nueva era digital y, en especial, conectar a nivel emocional con el personal que se tiene a cargo en las empresas, haciendo vida las mejores prácticas de la motivación en los equipos, etc.

Se necesitan líderes conectados con sus equipos de trabajo, que apoyen al desarrollo de competencias y compromisoque equivale a habilidades duras y blandas en los equipos de trabajo. Ante este escenario, te pregunto, empresario, ¿te atreves a desarrollar un liderazgo más estratégico y dejar en el pasado ese liderazgo basado en la amenaza que no valora el buen desempeño y la productividad esperada?

\section{Fortalecer la digitalización de los negocios:}

Es fundamental que las empresas puedan darle la importancia- y, por tanto, la respectiva asignación de recursos - a la digitalización de sus negocios, ya que en la actualidad ha quedado demostrado el impacto positivo y de gran alcance que este tema tiene en las empresas en la continuidad de los negocios. Utilizando los canales digitales también se ha fortalecido la formación en tiempo real y en forma más directa para conocer la opinión del cliente, el teletrabajo, y otros.
En el marco de esta dimensión, en la práctica se ha podido comprobar que es imperativo la incorporación de celulares inteligentes, Tablets, laptops y otros dispositivos para atender a reuniones de trabajo, recibir pedidos de clientes, coordinar entregas, etc. Al respecto de este punto, quiero invitar a los empresarios a que puedan darse permiso de pensar en la apertura de una sucursal digital de sus negocios y con ello poder lograr un mejor posicionamiento de su marca y, por tanto, la continuidad de sus negocios.

Además, en el marco de las estrategias de digitalización se podría considerar apostarle al diseño y desarrollo de una estrategia de marketing digital para sus negocios. En ese sentido, sería importante considerar la contratación de una persona que sea especialista en estrategias digitales ya sea interno o externo y darle el presupuesto pertinente. Esta podría ser una buena opción si lo que esperas es que en los próximos tres o seis meses la empresa se convierta en una opción preferente entre tus clientes actuales y nuevos. ¿Te gustaría digitalizar de manera efectiva tu empresa? ¡Te diré que ya es tarde!

\section{Fortalecer el Trabajo en Equipo: multitarea y multigeneracional}

Es importante hacer una revisión de funciones entre su personal actual para evaluar habilidades y tomar decisiones sobre la necesidad y pertinencia de hacer una reasignación de funciones, no olvidando la integración de los equipos multigeneracionales. Toda esta gestión se puede realizar luego de fortalecer el liderazgo al que hacía referencia en el tercer punto, además de tener claras las nuevas oportunidades de negocio a alcanzar y las debilidades que se deben afrontar. 
En la actualidad las empresas deben apostarle a que sus líderes sean capaces de darle vida al cumplimiento de nuevos objetivos de las empresas porque comprenden, creen en esos objetivos, sobre todo en un contexto nuevo y lleno de incertidumbre como es el que se vive actualmente debido a la pandemia. Asumir y cumplir nuevos objetivos presenta la posibilidad de incrementar la efectividad en los equipos de trabajo, subiendo el nivel de satisfacción con las actividades que realizan. Por eso es relevante implementarlo ya que según algunos estudios se ha demostrado que las personas felices en sus trabajos son $12 \%$ más productivas que las que no lo son. ¿te gustaría tener $12 \%$ más de margen?

\section{Fortalecer las herramientas de gestión de personas utilizando el Coaching}

Si los empresarios consideran las $4 \mathrm{~F}$ anteriores, sus empresas ya están apuntando a entrar a un proceso de transición y actualización empresarial que puede tener efectos positivos como es un buen posicionamiento de la marca, de sus productos 0 servicios de alto impacto.

Con las experiencias y aprendizajes que he tenido como business coach quiero decirles que estamos en un gran momento de la historia en el mundo de los negocios y es un tiempo de grandes desafíos y retos. Por eso es sumamente necesario realizar este tipo de evaluación en las empresas que sirva para identificar las áreas prioritarias para ser innovadas. A partir de esa identificación de áreas prioritarias para la innovación tu empresa se puede preparar para dar el soporte estratégico que necesita tu personal para conocer, comprender y asumir en la práctica nuevos objetivos. Es en este momento que el uso de herramientas como el coaching en la gestión de personas adquiere suma relevancia, pues es lo que permitiría que se logre un equilibrio sano en la cultura organizacional digital que tu empresa necesita.

Es necesario que todas las gestiones del personal se diseñen y se hagan partiendo de la mejor versión de cada miembro del equipo, para ello el uso de los procesos de coaching, se vuelve una ventaja competitiva, pues influye de manera positiva en todas las áreas de la empresa. Esto contribuye a apoyar los procesos de motivación y compromiso de los colaboradores llevándolos a dar un servicio lleno de energía, enfocado y genuino con cualquier tipo de cliente que encuentre sea en el ámbito digital, sea distante, estresado, exigente, informado, etc. ¿Te gustaría poder implementar un plan de motivación utilizando el coaching?
La suma de estas 5 áreas fortalecidas genera empresas que analizan de manera objetiva sus fortalezas, oportunidades, debilidades y amenazas lo que las lleva a poder generar estrategias más enfocadas en el desarrollo del liderazgo con el que se gestionan a los equipos y puedan pasar al siguiente nivel de desarrollo. Además, la integración de estas áreas también puede apoyar los procesos de la digitalización de sus negocios, logrando darles a los clientes el nivel de satisfacción deseado y superando las expectativas de ellos, gracias a la rapidez en la atención de sus necesidades. El uso de los canales digitales permite llegar más cerca de los clientes con una sonrisa digital única y especial que marca la diferencia.

Además, una empresa que capacite a sus líderes en el uso de la metodología de coaching tiene como resultado equipos inspirados, motivados, comprometidos, con bajos niveles de stress y bajos niveles de enfermedades y una reducción sustancial de ausentismo laboral por incapacidades.

Para finalizar, las empresas que se comprometan con sus propios procesos de transición desde la alta gerencia, lograrán una nueva empresa con metas líderes que son las que van más allá de solo cumplir metas de la forma tradicional que hemos conocido hasta hoy, sino que van más de la mano de un liderazgo más humano.

¿Te atreves a implementar este camino? Espero que sí y si necesitas apoyo estoy a tus órdenes. ¿Por qué no soñar con empresas llenas de recursos digitales y de gestión más humana de los equipos de trabajo con el que cuentas en este momento? ¿A quiénes de los que están leyendo le gustaría posicionar sus marcas en nuevos mercados? ¿profesionalizar la gestión empresarial? ¿qué te impide hacerlo vida? ¿cuándo quieres comenzar a escribir esta nueva historia empresarial?

¿Cómo te gustaría ser recordado como empresario exitoso que se atrevió a entrar en un proceso de digitalización para lograr afrontar estos nuevos desafíos? Lo más importante de este artículo es que te respondas a ti mismo y actúes hacia el siguiente paso de transición a la nueva realidad en el mundo de los negocios. 